\title{
Government report highlights the lack of clinical trial protection in the US
}

The system that is intended to protect human subjects in the US from the potential dangers of biomedical research is in jeopardy. It has become increasingly ineffective in recent years as the nature of research has expanded and should be reformed to reflect these changes. This is the overarching conclusion of a new report released on June 11th from the watchdog Inspector General of the Department of Health and Human Services (HHS), June Gibbs.

The report states that concerns about protection for human subjects become 'even more significant in view of current intentions to substantially increase Federal spending on biomedical research' and says that the plans to double the National Institutes of Health (NIH) budget in the next five years would mean a 'five-fold increase in those participating in clinical trials.'

There are around 50 million patients eligible to participate in trials each year in the US (who suffer from a chronic illness that is being targeted by an investigational treatment), but only four to six million patients per year ever participate. Nevertheless, the criticism of Institutional Review Boards (IRBs) - the bodies required by Federal law to review study protocols-comes at a time of growing public awareness of, and desire to participate in, clinical trials, evidenced by the increased demand for health care providers to give access to experimental studies especially for lifethreatening illnesses.

Its also coincides with efforts to enroll what could be described as more vulnerable groups in clinical trials. The HHS, Food and Drug Administration (FDA) and NIH want to widen the demographic profile of trial participants by including larger numbers of women, pregnant women (Nature Med., 3; 1179, 1997), ethnic minorities and children in studies, thus more closely reflecting the heterogeneity of end-users of medicine. And in May, the American Society for Clinical Oncology called for increased participation of elderly people in cancer trials.

The report points out that IRBs were created in the 1970 s in a climate where research was highly localized, and often confined to a single researcher studying a small group of patients at one site. But over the past 20 years, the scope of biomedical research has grown far beyond that which was envisioned and IRBs are now operating in a research culture that is 'significantly transformed.'

Not only is the proportion of research funded by industrial sponsors much greater, but budgetary constraints on academic centers and hospitals have intensified, forcing them to place greater reliance on clinical trials as a source of revenue. The report cites one anonymous example of an academic site that derives one quarter of its operating budget ( $\$ 200$ million) from clinical research activities.

The report stresses that many of today's research protocols are for multicenter trials involving thousands of subjects, numerous investigators and institutions spread out across the country. As a result, America's 3,000-5,000 IRBs have an increased workload: some assess 2,000 protocols per year and there has been an average 42 percent rise in initial reviews during the past five years. They are ignorant of problems or protocol changes at other sites. In addition, the advances in biomedical research such as genetic testing and gene therapy have wide-ranging ethical implications for human subjects that need special consideration, and which IRBs are illequipped to provide.

Today's boards are asked to review 'too much, too quickly' and with 'too little expertise,' and are prone to possible conflicts of interest that may compromise their independence, the report says.

The document is the fourth Federal paper in recent years to draw attention to failings of the IRB system, and the realization that the system is in trouble has permeated through the field (Nature Med. 4; 9, 1998). The question remains of how to effect repair.

The Inspector General calls on the HHS to overhaul the system by easing the procedural requirements imposed on the boards. In return it asks that IRBs be held more accountable and become more independent from the institutions they serve by appointing more non-scientific members who are not employed by the institution housing the IRB. It asks that they make on-site follow-ups a priority, that they themselves be subject to performance review, and that they receive more feedback information both from the FDA and the Data Monitoring Safety Board. It requests that IRB members undergo training and education, a task that it specifically charges the NIFi to carry out. These measures will require financial backing and are set to increase the pricetag of clinical trials.

Ruth Faden, chair of the 1994 Advisory Committee on Human Radiation Experiments, admits that HHS did come through with some changes in response to similar concerns raised in her report, but only after a lengthy delay. Last year, the NIH began a grant program for research into how to improve informed consent, and they have also released money to support training in research ethics. But Faden, director of the Bioethics Institute at Johns Hopkins, says that although this will slowly increase the pool of experts working in the field of human subject protection, it is far too small a measure to solve the problem. Faden suggests that what may be needed is an HHS-independent assessor.

Leroy Walters, director of Bioethics at the Kennedy Institute, points to an even darker problem underlying clinical trials in the US: unlike Europeans, Americans enrolled in experimental trials have no accidental damage insurance. Although the sponsor covers all medical costs of the trial, there is no protection against complications that arise as a result of the trial after it has finished. This, says Walters, underscores the very problem that the report addresses-the rights and safety of people involved in trials are not protected and often they have no idea of what it really means to be a human experimental subject.

KaREN BirminghaM, NeW York \& Marlene Cimons, Washington, D.C. 